\title{
Hacia una nueva subjetividad: La figura del padre en la novela sentimental y La Celestina
}

\author{
Anna Casas Aguilar \\ Universidad de British Columbia, Canadá
}

La Celestina (1499) de Fernando de Rojas ha sido leída como una obra que parodia las premisas del amor cortés; entre ellas, el ennoblecimiento del amante, el secreto de amor y la divinización de la amada. Siendo esta una parodia total (Lacarra 13, Iglesias 77), toma en consideración tanto la forma como la fábula y abarca también cada uno de sus personajes. Así, Rojas realiza una burla del modelo sentimental en Calisto, que es una clara caricatura del amante cortés, en Melibea, parodia de la amada perfecta y en los criados Pármeno y Sempronio, caricatura de los intermediarios ideales. A pesar de que los padres de los amantes no están presentes en igual medida en las novelas sentimentales, el padre y la madre de Melibea -Pleberio y Alisa - son también parte de esta parodia. En el presente artículo analizo la figura del padre en las novelas sentimentales Siervo libre de amor (1440) de Juan Rodríguez del Padrón, Cárcel de amor (1492) de Diego de San Pedro y La Historia de Grisel y Mirabella (1495) de Juan de Flores, con el fin de contrastar a Pleberio con el modelo de padre que nos ofrecen estas novelas sentimentales. Con mi análisis quiero demostrar que, en La Celestina, encontramos una parodia de la figura del padre de la novela sentimental, y que a la vez la figura paterna en el texto de Rojas presenta una nueva subjetividad en la que el padre ha dejado su deseo de ser imparcial, de representar la ley y la justicia, y asume una posición más humana en relación con la muerte de su hija.

En su estudio sobre la novela sentimental, Regula Rohland de Langbehn nombra entre los rasgos y motivos esenciales de la novela sentimental el padre cruel (17) y explica que su función consiste en «separar defin tivamente a los amantes reales o presuntos» (49). El padre es uno de los impedimentos que los amantes encuentran para consumar su amor. Sin embargo, el padre no es una figura imprescindible para que una obra se considere dentro de dicho género, aunque sí es un personaje que aparece en numerosas ocasiones y cuya actuación tiene importantes consecuen- 
cias en que la fábula siga por el cauce tradicional. De hecho, existen en el género de la novela sentimental padres ausentes, como el padre de Lucenda en el Tractado de amores de Arnalte y Lucenda (1491), de Diego de San Pedro. Sin embargo, en las siguientes páginas he optado por comparar a Pleberio con otros padres presentes, como son los padres en el Siervo, en Cárcel y en Grisel, ${ }^{1}$ ya que, como Antonio Cortijo Ocaña explica siguiendo la lista de Keith Whinnom (Ocaña 7), estas obras pueden considerarse como canónicas dentro del género y "han entrado con letras de molde en las historias literarias» (9). Además, Pleberio es un padre presente y en este sentido me parece esencial entenderlo como burla al modelo de padre presente de la novela sentimental.

En la novela sentimental anterior a La Celestina la figura del padre es una figura relacionada con la ley y el poder - un rey en las tres novelas que nos ocupan- y relacionado con la imposibilidad de la consumación del amor carnal de los amantes; el padre establece los límites del deseo, y no sólo representa el estatus familiar y su preservación, sino que es el responsable y protector del honor de la hija, de su cuerpo, y de la casa paterna como un espacio impenetrable. Como consecuencia, suele ser la figura paterna la que impone el castigo y la pena de muerte de los amantes cuando el amor se ha consumado. La sumisión y resignación de la hija o del hijo al poder paterno pone a la joven pareja en tensión con la figura del padre, una tensión que normalmente se resuelve en la muerte impuesta por parte del progenitor. Asimismo, a la frialdad, dureza y crueldad del padre frente al deseo de los amantes, se oponen el llanto y las súplicas de la madre. Si consideramos estas características generales, nos damos cuenta de entrada de que Pleberio es, sin lugar a dudas, un padre que dista enormemente de dicho modelo. Analicemos ahora las características de los padres presentes en las tres novelas sentimentales que nos ocupan.

En primer lugar, es esencial señalar que los personajes principales, la pareja de amantes, se presentan en relación con las figuras de sus antecesores. Esto los presenta como individuos con nobleza de sangre y de alto rango y linaje. En el Siervo, antes de dar paso a «la historia de los dos amadores», se explica que Ardanlier es "hijo del rey Creos de Mondoya e de la reyna Senesta» (83) y Liessa hija del "grand señor de Lira» (84). En la Cárcel, el mismo Leriano, preso en la cárcel, narra al Autor su linaje y le deja saber su orfandad, a la vez que anuncia el linaje de Laureola, que es hija del rey Gaulo de Macedonia: "Tú sabrás que yo soy Leriano, hijo del duque Guersio, que Dios perdone, y de la duquesa Coleria. Mi naturaleza es este reino do estás, llamado Macedonia. Ordenó mi ventura que me enamorase de Laureola, hija del rey Gaulo (...)» (71). El primer tratado de Grisel y Mirabella empieza de un modo muy similar, esto es, con la

1.- A partir de ahora tomaré estas abreviaturas para referirme a las obras Siervo libre de amor, Cárcel de amor y La Historia de Grisel y Mirabella, respectivamente. 
presentación rey de Escocia, padre de Mirabella, y su característica más reconocida, su justicia: "En el reino de Escocia hubo un excelente Rey de todas virtudes amigo, y principalmente en ser justiciero; e era tanto justo como al mesma justicia» (54).

La similitud de estos comienzos se percibe a simple vista, a pesar de que naturalmente encontramos ciertas variaciones. Estas presentaciones con que se abren las novelas sentimentales nos sitúan en un ambiente cortesano y además nos indican que los protagonistas forman parte de un sistema de valores muy específico y estricto que deben respetar. Un sistema de valores amparado por ciertas leyes, morales y judiciales en el que la figura real, solapada con la figura paterna, es una autoridad doble, familiar y legislativa a la vez.

Es importante notar que en estos principios, cuando la figura del padre es referida, se explica que éste inspira ciertos sentimientos, entre ellos el miedo, el respeto, el temor y la imposición y aceptación de la ley. En el Siervo, Ardanlier teme a su padre: "E por la semblante veía el rey Creos muy odioso era a su hijo Ardanlier, con grand themor que del avía» (...). Aunque parece que este miedo hace más fuertes las pasiones del joven: "E las fuerças del temor acrecentaua en los coraçones de aquellos las grandes furias del amor de tal son» (84). En la Cárcel, también se hace implícito que, como buen vasallo de su rey, Leriano no debiera dejarse llevar por su pasión hacia Laureola "Ordenó mi ventura que me enamorase de Laureola, hija del rey Gaulo, que agora reina, pensamiento que yo deviera antes huir que buscar» (71). En el caso de Grisel, el respeto es inspirado cuando el rey no sólo no acepta a ninguno de los muchos pretendientes que piden la mano de Mirabella, sino que además la encierra en un castillo para que nadie la pueda ver.

Por otro lado, en todos los casos la pareja de jóvenes amantes son hijos únicos. Esto implica una mayor responsabilidad mutua, tanto de los protagonistas hacia sus padres, como de los padres hacia los hijos, que son los únicos herederos de sus riquezas y portadores del honor familiar. Los hijos, en palabras de Pablo Alcázar López y José A. González Núñez, «aseguran o ponen en peligro la transmisión de la sangre noble y, como consecuencia, de la herencia real» (35-36).

En consecuencia, el padre protege su espacio, cuyos confines y fronteras están claramente delimitados. Las relaciones entre los amantes, por lo tanto, sólo pueden tener lugar o fuera del espacio parterno, como en el caso de Ardanlier y Liessa, o cuando el padre no está atento a lo que sucede en el interior de sus confines. En la Cárcel, Persio acusa a Leriano de haber tenido relaciones con Laureola, traicionando al rey y penetrando en el espacio paterno cuando él estaba durmiendo: "díxole afirmad mente que Laureola y Leriano se amavan y que se veían todas las noches después que él dormía» (93). Más adelante, cuando Persio denuncia a Leriano, se repite el detalle de que el rey se había acostado, y así no po- 
día estar atento a lo que sucedía: «(...) toviste osada desvergüenza para enamorarte de Laureola, con la cual en su cámara, después de acostado el rey, diversas vezes has hablado» (94). Si, al dormir, el rey está ausente y descuidado y los límites de su espacio son más vulnerables, la respuesta del rey a la acusación será proteger a la hija con paredes más fuertes, y encierra a Laureola en una "dura cárcel» (107). Laureola describe su nueva situación así: "con gruesas cadenas estoy atada, con ásperos tormentos me lastiman, con grandes guardas me guardan, como si tuviese fuerça para poderme salir» (107). Otro claro caso de esta necesidad de defensa de confines y espacios por parte del padre es el de Grisel. Esta historia repite el motivo de la joven encerrada en una torre como medio de protección de su cuerpo y de su honra, y hace hincapié en la necesidad de ahuyentar posibles miradas: "De manera que, sabido por el rey, la hizo meter en un lugar muy secreto que ningún varón verla pudiese, por ser su vista muy peligrosa, porque el desastre con buenas guardas resiste» (55). Evitar la primera mirada es para el padre de Mirabella impedir que la hija pueda despertar cualquier deseo en otros hombres, a la vez que impedir que ella pueda desear a nadie. De este modo, vemos como denominador común de los padres en la novela sentimental su gran recelo en proteger al hijo o la hija.

La gran responsabilidad que estos reyes sienten hacia sus progenitores tiene como efecto que ciertas cualidades de los mismos reyes, que de entrada deberían ser positivas, se desarrollen en demasía y acaben siendo negativas por su exageración. Algunos ejemplos de esto son cómo la perseverancia del rey Creos acaba convirtiéndose en crueldad y cómo el deseo de justicia extrema del padre de Mirabella acaba por convertirlo en injusto. En el Siervo, el padre de Ardanlier es un rey perseverante que busca a su hijo durante siete años hasta encontrarlo: "E cumpliendo los siente años que byuía en aquel solo desierto, dados a la vida solitaria, su padre, rey Croes, rrey de Mondoya, desterrado de vn solo hijo que tanto amava, no tardó embiar en su alçançe por estrangeras partidas. E muy lastymado Rey no pudo durar que no fuese en la busca» (88). Sin embargo, al encontrar a su hijo se pone de manifiesto la crueldad del monarca, que es de hecho una característica compartida por los padres presentes de la novela sentimental. Siendo Creos el más cruel de los reyes que vamos a analizar, vale la pena detenerse en su conducta. Cuando encuentra a Liessa, el rey la insulta, y ella cae a sus pies, pidiéndole merced; él responde con «arrebatado furor» (89):

Traydora Lyessa, aduersaria de mí! Demandas merçedal que embiudaste de vn solo hijo, que más no avia, enduzido por ty rrobar a mi, su padre, e fuyr a las glotas e concauidades de los montes por más acreçentarme la pena! ¡E deviérasgelo estrañar, y no consentyr; desuiar, y 
no dar en consejo! ¡Demandas merçed! Rrey soy; no te la puedo negar; mas dize el verbo antigo: «Merçed es al rey vengarse de su enemigo. (89)

Como vemos, el padre de Ardanlier no sólo responde como padre gravemente ofendido, sino que toma su cargo de rey como explicación de su poder. Le dice a Liessa que no le puede negar su merced, pero que, como Rey, también tiene derecho de vengarse de su enemigo, que en este caso es ella por haberlo separado de su único hijo. Después de estas terribles palabras, el rey Creos actúa inhumanamente con alguien que ha pedido su perdón y que es además una mujer joven, embarazada, y que ama a su hijo. La conducta del rey no cambia a pesar de saber de este embarazo: «E en punto escrymió la cruel espada contra la adfortunada Lyessa; la qual, agramennte llorando, fincada la rodilla delante de[é]l gritando y dizinedo tales temerosas palabras: - «A[h] señor, piadat de tu verdadero nieto que traygo en mis yjadas! ¡No seas carniçero de tu propia sangre!»» (89).

La espada del rey Creos de Mondoya atraviesa las entrañas de la joven Liessa y a la criatura que ella estaba esperando al mismo tiempo (90), y así el rey mata a su heredero. Vemos con claridad que, para el rey, es más importante salvaguardar su honor que salvar su propia descendencia, y asesina, llevado por su furia, la sangre de su propia sangre. Rohland de Langbehn aclara que la violencia en esta obra "se ejerce por razones de estamento: el rey Croes no mata a Liessa por celos, sino porque no es par de su hijo" (63-64). La atrocidad de la escena es doblemente subrayada cuando Lamidoras relata a Ardanlier lo sucedido. Lamidoras dice a Ardanlier que su padre es un segundo Nero, «actor de las crueldades» (92), describe la ferocidad con que cometió el delito y lo pinta como "cruel más que las fieras animalias brutas, que no han sentido de piedat» (92-93 .

Éste no va a ser el único caso de crueldad y violencia física, aunque sí el más brutal. En el caso de Grisel, el rey de Escocia, en vista de que Grisel y Mirabella no quieren confesar la verdad, «mandólos muy cruelmente atormentar; tanto que las llagas que sofrían eran de mayor dolor que la misma muerte que esperaban" (61). Más adelante, el Autor narra que, por mandado del rey, Mirabella fue por fuerza quitada de los brazos de su madre, "la cual en una rica camisa despojaron para recebir la muerte, veyendo arder ante sí las encendidas llamas del fuego que la esperaban» (83). Ciertas cualidades en exceso acaban por convertirse en negativas. En la Cárcel, el rey, al conocer a través de las acusaciones de Persio que su hija y Leriano tienen relaciones, se muestra primero turbado, dudoso, pensativo y medita largamente su respuesta: «Turbado el rey de cosa tal, estovo dubdoso y pensativo sin luego determinarse a responder, y después que mucho dormió sobre ello, tóvolo por verdad, creyendo, segund la virtud y auctoridad de Persio que no le diría otra cosa; pero con esso, primero que deliberase quiso acordar lo que debía hazer.» (93) El deseo 
del rey es ser objetivo e imparcial, quiere actuar con frialdad, serenidad y discreción. Además de defender su propio honor, siente que su conducta, en un caso que lo afecta tan personalmente, puede hacerle perder o preservar su fama como rey justiciero:

Si el yerro desta muger quedase sin pena, no sería menos culpante que Leriano en mi desonra. Publicado que tal cosa perdoné, sería de los comarcanos despreciado y de los naturales desobedecido, y de todos mal estimado, y podría ser acusado que supe mal conservar la generosidad de mis antecesores; y a tanto se estendería esta culpa, si castigada no fuese, que podríe amanzillar la fama de los pasados y la onra de los presentes y la sangre de los por venir; que sola una mácula de mi linage cunde toda la generación. Perdonando a Laureola sería causa de otras mayores maldades que en esfuerço de mi perdón se harían (...) (111)

El rey siente que, si perdona, va a ser despreciado y desobedecido por sus súbditos, ya que mostrará que la ley no se aplica en ciertos casos, que él es parcial e injusto cuando se trata de su propia culpa. De resultas, se torna un gran defensor y seguidor de la ley y la va a implantar a raja tabla por ser este el caso de su hija. Su sistema de valores está basado en su fama como rey justiciero y no dejarse llevar por su subjetividad. El castigo es la única solución que él ve para conservar "la generosidad e sus antecesores» y que no se manche su nombre. El rey termina su parlamento haciendo referencia a la existencia de unas leyes determinadas y cómo el incumplimiento de las mismas le perjudicaría enormemente: «Pues ya veis cuanto más me conviene ser llamado rey justo que perdonador culpado, que lo sería muy conocido si, en lugar de guardar la ley, la quebrase, pues a sí mismo se condena quien al que yerra perdona» (111). Así, a pesar de la supuesta serenidad y de la equidad superficial, el rey en realidad está siendo parcial, y tomando la justicia más seriamente que en ningún otro caso porque este juicio se trata de su hija.

Grisel es sorprendentemente similar. ${ }^{2}$ Cuando el rey se entera de la relación entre Grisel y Mirabella, quiere ser discreto y no dejarse llevar por sus pasiones y enojos: "con gran discresión buscó manera cómo ambos lo tomasen en uno» (58). Quiere ser íntegro y equitativo: «no quiso usar de rigor ni de enojo accindetal; mas, como si fuesen sus iguales, con ellos se pudo a justicia» (58). Sin embargo, su equidad va poco a poco desvaneciéndose. En la novela se explicita que las leyes son claras, y que el culpable de la relación ilícita debe pagarlo con la muerte, y el otro deberá ser desterrado por toda su vida (58). El rey intenta ser imparcial y primero 
organiza una disputa intelectual entre Brazaida y Torrellas, pero como el problema no se resuelve, pide consejo a los letrados, doce hombres, jueces «los cuales dieron sentencia que Mirabella muriese; y fundaron por muchas razones ser ella mayor culpa que Grisel» (62). Una vez conocida la sentencia, el rey explica a la reina la gran necesidad de aplicar la ley, ya que, como sucedía en la Cárcel, él es modelo de todos los ciudadanos: "Yo quisiera que consideraras como la persona del Rey es espejo en que todos miran y sus obras conviene ser tales que resplandezcan entre todas las otras gentes, principalmente en la justicia, como sea a todos mas menesterosa» (79).

En este parlamento el padre de Mirabella muestra también que, para él, lo más importante es el honor, y que a pesar del gran amor que siente por su hija, si para conservar su honor tiene que perder su descendencia, lo hará. Veamos que utiliza la palabra trabajar dos veces, no para referirse a un trabajo que le haya dado riquezas, sino un trabajo que le ha proporcionado elogios, y que éste está por encima de su poder:

(...) aquello que desde mi primera edad me he trabajado por guardar, no sería bien ahora, en mis postrimeros días, lo perdiese: pues en el fin de la vida está el loor; y si yo gasta aquí he administrado justicia, cuando en mi hija no la hiciese, no me podría loar de justo; que quien de sí mismo no face justicia, no la debe hacer con otro; más primero deben los nobles punir a sí mesmos que a sus siervos y yo, según el mucho amor que con Mirabella tengo, ante querría sufrir la muerte que darla a ella. (...) pues yo mas quiero tener loor de virtuoso y justo que de poderoso; y la razón es esta: que todos mis reinos y señoríos mis antecesores los ganaron y yo no me puedo loar haber ganado, salvo lo que dellos me quedó; mas si en mí alguna virtud hay de aquella me precio; así que, pues sola justicia es mi vitoria y lo más loable de mi estado, no quiero perder aquello que con tan gran estudio y trabajo he ganado (...) (79-80)

El padre de Mirabella no parece un padre amantísimo y virtuoso, ni tampoco un monarca totalmente justo, a pesar de «que se apoya un consejo juristas y antepone la razón de estado a los intereses personales y dinásticos, tal como propone la teoría política renacientista“ (Alcázar y González 43). Como vemos, el rey está enormemente preocupado por ser injusto. Es un momento clave en el que va a mostrar a sus súbditos cómo actúa en un caso personal. Sin embargo, para evitar tomar una decisión errónea llevado por sus sentimientos, decide olvidar o negar su papel de padre y aplicar la ley como rey con más firmeza que nunca. Niega sus sentimientos, su natural implicación subjetiva, y afirma que «la justicia 
era más poderosa que el amor» (80). ¿Pero puede realmente un padre dejar de serlo? Citando a Mercedes Roffé, este juicio «no puede ser para él sino objeto de sentimientos ambivalentes» (184).

Tanto en el Siervo, como en la Cárcel y en Grisel, se hace evidente la crueldad del rey y que sus ideales de justicia son demasiado elevados. Las otras personas del reino lo advierten también y avisan a estos reyes sobre su gran error. Las madres son un claro ejemplo de esto. Sus sentimientos de piedad, perdón y amor, como bien apunta Dinko Cvitanovic en el caso de Grisel (191), contrastan fuertemente con la justicia implacable del rey. Así, los llantos y las súplicas de las madres subrayan la crueldad del rey, a la vez que nos hacen ver su dureza e intransigencia, ya que los reyes nunca muestran arrepentimiento ni duda hacia sus actos. Ejemplos de esto los encontramos en la Cárcel, cuando el Autor explica cómo la reina suplica por Laureola. En este pasaje se ponen claramente en contraste la figura masculina y femenina y los valores del padre y de la madre:

Dezíale la moderación que conviene a los reyes, reprehendíale la perseverança, de su ira, acordávale que era padre, hablávale razones tan discretas para notar como lastimadas para sentir, suplicávale que, si tan cruel juizio dispusiese, se quisiese satisfazer con matar a ella (...). Mas tan endurecido estava el rey en su proósito que no pudieron para con él razones que dixo ni las lágrimas que derramó; y assí se bolbió a su cámara con poca fuerça para llorar y menos para bevir. (112)

En Grisel hay una actuación similar de la madre y sus doncellas. El cuerpo de la madre y sus movimientos indican su humildad y sumisión al querer paterno: "la Reina y con ella todas las damas se ponen ante los pies del Rey, humildemente, suplicando por la vida de Mirabella; al cual ningunos ruegos vencer pudieron» (79). De nuevo, la madre suplicando por la salvación de la única hija es una figura que resalta la inclemencia del rey. Ella le hace memoria del valor de sus riquezas y de su poder, que se pierden sin descendencia, y de la importancia de amar:

Pues ¿qué valen tus grandes villas y ciudades cuando fijos en que sucedan no tuvieses? Y como los padres a los hijos más que a sí mesmos aman, ¿en cuál humanidad cabe que de sí mesmo faga ninguno justicia? Y pues a sí no ama, ningunos bienes posee, por donde es mejor menguar en la justicia que sobrar tanto en la crudeza. (79)

Pero no son las madres las únicas que suplican al rey y quieren que vea su injustica. En Grisel "muchos le suplican, hombre y mujeres, condes, ducques, grandes señores lágrimas de la madre desconsolada» (81). En el caso de Siervo, la infanta Yrena escribe una carta al rey y le dice que con 
su crueldad ha perdido su fama de buen padre y de buen rey y que ahora es considerado un rey cruel y falto de justicia (99). En la Cárcel encontraremos numerosos ejemplos de súplicas y avisos al rey, entre ellas las de Leriano, que le dice que no está actuando con suficiente justicia confiando en Persio y desconfiando de él (98); o la carta de Laureola al rey (109-110), en el que la hija le pide penitencia al padre, y que vamos a analizar junto con el parlamento de Melibea a Pleberio. También el cardenal de Gaussa advierte al rey, le pide que vuelva a su reposo, le dice que Laurola es inocente y que él es un rey cruel e injusto, que se ha dejado llevar por la ira y, como veíamos en el Siervo, que está siendo verdugo de su propia sangre:

Assí, buelve en tu reposo, que fuerce lo natural de tu seso al acidente de tu ira. Avemos sabido que quieres condenar a muerte a Laureola. Si la bondad no merece ser justiciada, en verdat tú eres injusto juez. No quieras turbar tu floriosa fama con tal juizio, que, puesto que en él uviese derecho, antes serías, si lo dieses, infamado por parte cruel que alabado por rey justiciero. (...) No seas verdugo de tu misma sangre, que serás entre los ombres muy adeado; no culpes la inocencia por consejo de la saña. (109-110)

El padre responde tajante que él no puede perdonar, no puede entrar en razón y admite «Mas bien sabés cuando el coraçón está embargado de pasión que están cerrados los oídos al consejo; y en tal tiempo las frutosas palabras, en luhar de amansar, acrecientan la saña, porque reverdecen la memoria la causa della» (110). Acepta que su corazón está llevado por la pasión y la saña, y en dicha irracionalidad se fundamenta su deseo de justicia extrema.

Una vez analizadas las características de estos padres presentes en tres novelas sentimentales, pasemos a estudiar sus semejanzas y diferencias con el personaje de Pleberio en La Celestina. Antes de empezar con el estudio de Pleberio en relación con las anteriores novelas sentimentales, me parece conveniente apuntar brevemente algunas de las lecturas más importantes que la crítica ha hecho sobre este personaje. Pleberio ha sido, por lo general, estudiado a partir de su lamento final. Dos son las interpretaciones más comunes de dicho lamento, que no están en discordia entre ellas: una que analiza su llanto como parte de la tradición literaria (Vicente, Wardropper, Severin, Uriarte Rebaudi, Gerli) y otra que entiende el llanto final como prueba de la visión nihilista del mundo de La Celestina y de su finalidad moralizante (Vicente, Ripoll, Ayllón, entre otros). Uno de los grandes desencuentros entre la crítica es si el lamento final debe interpretarse como la visión del mundo del mismo Rojas (Fraker, Ripoll) o como expresión individual de uno de los personajes. Frente a dichas teorías, encontramos las consideraciones de estudiosos como Marcel Bataillon 
(en Wardropper 140), María Rosa Lida de Malkiel, ${ }^{3}$ o Yolanda Iglesias que piensan que Pleberio es un personaje cómico, y las lecturas de James A. Flightner, Peter Dunn y James F. Burke, que argumentan que se debe considerar todo el personaje y no únicamente el lamento final para entender su peso y caracterización en la obra. Siguiendo la opinión de este último grupo de críticos, considero que es importante contemplar el conjunto de esta figura, especialmente si lo que queremos es entender la parodia que La Celestina hace mediante este personaje de la figura del padre de la novela sentimental. Argumento que Pleberio es un personaje cómico, y no trágico, y que su comicidad nace de todos los puntos de unión entre Pleberio y los padres presentes de la novela sentimental.

El principio de La Celestina, coincidiendo con la novela sentimental, presenta a Melibea como «muger moça muy generosa, de alta y sereníssima sangre, sublimada en próspero estado, una sola heredera a su padre Pleberio, y de su madre Alisa muy amada» (86). Se hace hincapié en que Melibea es la única hija de padres prósperos, y así única heredera, no de un reinado, pero sí de la riqueza considerable de una familia pudiente. La hija va ser la única heredera y la portadora del honor familiar. Como vemos, Pleberio es el personaje clave para situar a la familia en un espacio económico, social, y reconocemos de entrada que tiene dinero y poder. A diferencia de los tres padres estudiados en el capítulo anterior, Pleberio no es un rey y, por lo tanto, su relación con la ley es un tanto diferente. Si bien él no representa la ley legislativa, como lo hacían las figuras de los reyes en las novelas sentimentales estudiadas, en muchos sentidos entendemos que su papel como protector del honor de Melibea sí debería seguir el patrón tradicional del padre del género sentimental.

Como vemos en este comienzo y como correctamente señala James Flightner, a pesar de que Pleberio no habla hasta el acto XII, su rol es integral y se establece mucho antes de que él aparezca en escena (79). Con dicha lectura coinciden Peter Dunn, quien afirma que Pleberio está "from early on the looms large in the apprehensive fantasy os the other characters» (409) y María Rosa Lida de Malkiel, quien señala: «Peculiar de este personaje es su tardía entrada en escena, en el acto XII, a la vez que su presencia en el pensamiento de otros personajes desde el principio»(471). Efectivamente, Pleberio está en el imaginario colectivo de los otros personajes y su rol, en dicho imaginario, es el de la figura tradicional de padre como responsable y defensor de la honra de la hija, y como hombre cruel y defensor de la ley.

En diversas ocasiones los personajes hablan de Pleberio y lo describen como un ser que inspira miedo, temor, respeto de la ley. La primera vez es cuando Sempronio advierte a Celestina del riesgo de su empresa, una

3.- Pleberio es para Lida de Malkiel tanto una figura rídicula (480), como también un personaje que tiene una visión pesimista del mundo como caótica lucha (472). 
vez Celestina se ha decidido a ir a ver a Melibea a casa de su padre: «Piensa en su padre; que es noble y esforçado, su madre celosa y brava, tú la misma sospecha. Melibea es única a ellos; faltándoles ella, fáltales todo bien; en pensallo tiemblo; no vayas por lana y vengas sin pluma» (149). Sempronio teme que Celestina pueda ser descubierta y que Pleberio, como padre justiciero y cruel, ordene su muerte y también la de los otros implicados en la trama. Celestina, en el acto siguiente, cuando está caminando hacia la casa de Pleberio, habla consigo misma para darse ánimos y piensa en cómo no puede abandonar su trabajo: «Más quiero offender a Pleberio que enojar a Calisto» (154). Todo su monólogo se dirige a evitar sentir el miedo y subvertir el temor que la figura de Pleberio le inspira. En el décimo acto, Celestina le confiesa a Melibea que temía el poder de Pleberio "Visto el gran poder de tu padre, temía» (250).

James A. Flightner considera que Pleberio inviste el primer encuentro entre Celestina y Melibea, ya que es debido al padre que es necesario mantener el secreto (80). Ciertamente, Melibea acusa a Celestina de querer destruir la honra y casa de su padre, lo que prueba que la honra de la hija está en relación directa con la honra del padre: "¿Querrías condenar mi honestidad por dar vida a un loco, dexar a mí triste por alegrar a él, y llevar tú el provecho de mi perdición, el galardón de mi yerro? ¿Perder y destruýr la casa y honrra de mi padre por ganar la de una vieja maldita como tú?» (166). Sin embargo, como bien estudia Francisco Rodríguez Cascante (26-27), Melibea utiliza una retórica tradicional en su favor, para conseguir gozar de Calisto. La relación entre el honor de Melibea y la defensa que del mismo hace Pleberio se repite en varias ocasiones. Otro ejemplo es el onceavo acto, cuando, para darle la noticia a Calisto de que Melibea está enamorada de él, Celestina le dice a Calisto "más está a tu mandado y querer que de su padre Pleberio» (254).

Siguiendo con el imaginario colectivo de los personajes sobre Pleberio, y como Dunn muy bien analiza, una gran parte del doceavo acto se basa en el miedo que Pármeno y Sempronio tienen de Pleberio y de sus guardias. Las palabras de este crítico son las siguientes: "Through the lens of fear, they see in Pleberio an ogre whose home is a fortress manned by well-fed servants desiring nothing so much as fight» (410). En esta escena, Pármeno se burla de que Calisto lo haya enviado a él primero a la puerta de Melibea para el "encuentro del primer peligro» (261) y más adelante Pármeno y Sempronio comentan los escuderos de Pleberio "son locos» (267) y peligrosos. En definitiva, siguiendo la lectura de Dunn, se da en el imaginario colectivo un desplazamiento de la realidad de este personaje (410). Lida de Malkiel también apunta que los sentimientos que despierta Pleberio en los diferentes personajes son el cuidado, la vigilancia, el temor, la aprensión, la jactancia y el acatamiento (471). De este modo, Pleberio es heredero para los otros personajes de las características del padre de la novela sentimental, es decir, tiene las propieda- 
des de las figuras del padre que hemos estudiado en el Siervo, la Cárcel y Grisel. Celestina, Pármeno, Sempronio imaginan al padre como un ser terrible que defendería la ley con tanto ímpetu que todos los que forman parte de esta historia entre Melibea y Calisto se verían amenazados de muerte por esta figura

Sin embargo, la primera escena en la que Pleberio habla, en el doceavo acto, es una escena cómica, y se hace patente que la realidad de Pleberio es otra que la imaginada. Calisto ya ha penetrado el espacio familiar y ha establecido relaciones con Melibea en su alcoba. Pleberio está medio dormido y oye ruidos en la habitación de su hija, y en lugar de levantarse enfurecido y controlar qué está pasando, le pregunta a Melibea de dónde viene el alboroto. El padre cree cándidamente la explicación de la muchacha: Lucrecia ha salido a por agua (270). Como Yolanda Iglesias observa, Alisa y Pleberio «no protegen la honra de su hija, quizás por ineptos o confiados, y ni siquiera se levantan de la cama para comprobar la procedencia de los extraños ruidos que escuchan a altas horas de la madrugada» (105). Pleberio no es un padre vigilante, no está atento, no es un padre cuya imagen real despierte ni miedo, ni respeto, ni imposición de ley hacia su hija. También para Lida de Malkiel la entrada patética de este personaje contrasta con las alusiones que se hacen de él a través de los otros personajes: «Pleberio no se muestra, según lo harían esperar acumuladas alusiones, como un gran señor imperioso, rodeado de servidores, inflex ble celador de su honra» (471). Todo lo contrario, en su primera aparición Pleberio se presenta "padeciendo zozobra casi animal (...), inquieto por la seguridad de la hija y desvelado el menor ruido de su cámara» (471).

La siguiente escena en la que aparece Pleberio es totalmente cómica también, especialmente si consideramos el modelo de padre de la novela sentimental. Pleberio le pide a su esposa consejos sobre si casar a Melibea. Además de la ironía de referirse a la honra de Melibea cuando la chica ya ha perdido la virginidad, Pleberio está pidiendo consejo a su esposa. Recordemos que los padres de la novela sentimental que hemos estudiado no aceptaban nunca la súplicas de sus esposas. El contraste es evidente.

El tratamiento espacial en La Celestina, principalmente en relación con la figura de Pleberio, es uno de los grandes logros de Rojas. Desde la primera escena el espacio paterno ha sido penetrado y burlado: Calisto ha entrado en la huerta de Pleberio. Tanto este primer encuentro entre Calisto y Melibea, como la primera visita de Celestina son a la luz del día, en un momento en el que Pleberio debería estar vigilante. Sin embargo, no se hace referencia ninguna al padre, no sabemos si Pleberio está durmiendo, aunque lo más seguro es esté despierto, prueba de su descuido y distracción. Un padre advertido y vigilante nunca dejaría que ni un hombre ni una alcahueta conversaran con su hija. La misma Melibea utiliza la idea del espacio del padre y su invasión como metáfora de la 
pérdida de su honra y dice a Calisto "Que si agora quebrasses las crueles puertas, aunque al presente no fuéssemos sentidos, amanescería en casa de mi padre terrible sospecha de mi yerro» (266-267). Más adelante, Melibea, consciente de haber profanado el espacio y la ley paterna al haber perdido su virginidad, se culpa de haber quebrantado la casa de Pleberio: "¡O mi padre honrado, cómo he dañado tu fama y dado causa y lugar a quebrantar tu casa!» (290). Melibea también confesará a su padre con estas palabras que ha mantenido relaciones sexuales con Calisto: «Vencida de su amor, dile entrada en tu casa. Quebrantó con scalas las paredes de tu huerto» (338).

Otro de los elementos clave en torno a la burla del espacio paterno es el motivo de la torre, que David Hook analiza con detalle en su artículo. Hook explica que, mientras Pleberio edifica torres, Melibea se tira desde una de ellas (28), y que la torre es así símbolo de la construcción moral que Pleberio anhelaba. También Burke coincide en mostrar a Pleberio como constructor cuyo edificio moral finalmente se cae (348). Además, siguiendo a Hook, la mujer en la torre es un motivo medieval literario que se asocia con el poder que ejerce el hombre, padre o marido hacia la joven, en las narraciones amorosas de las novelas sentimentales, por ejemplo en Grisel. Según Hook, la utilización de Rojas de este motivo es un claro reverso del esquema: "Melibea is not locked in a tomer by her father to preserve her virginity; she locks herself in a tower away from her father after her virginity has already been lost» (29-30).

Un aspecto interesante para comprender en su totalidad la figura paterna es el parlamento de Melibea a Pleberio en el momento de su suicidio, que debe contraponerse a la carta que Laureola manda a su padre, el rey, pidiendo piedad. La gran discrepancia entre lo que dicen las dos hijas acentúa las grandes diferencias entre los padres. En la Cárcel, Laureola le dice a su padre que no es justo acusarla y castigarla con la muerte, pero que, a pesar de su injusticia, él es el padre y el rey, y ella es hija y súbdita, y así va a acatar sus órdenes: «(...) si te plaze matarme por voluntad, obra lo que por justicia no tienes, porque la muerte que tú me dieres, aunque por cause de temor la rehúse, por raxón de obedecir la consiento, aviendo por mejor morir en tu obediecia que bevir en tu desamor. (...) Sin dubda, yo deseo tanto mi vida por lo que a ti toca como por lo que a mí cumple, que al cabo so hija» (117). Así, Laureola acepta su muerte como consecuencia del deseo paterno.

En La Celestina, el parlamento de Melibea es totalmente opuesto al de Laureola. Desde la torre de la que se va a suicidar, Melibea le dice a su padre que ama a Calisto y que no quiere vivir sin gozar de él. No hay ni un mínimo vestigio de miedo al padre, ni de acatamiento de sus órdenes por parte de Melibea. La joven es consciente del dolor que causará a su progenitor "Gran sinrazón hago a sus canas; gran ofensa a su vejez; gran fatiga le acarreo con mi falta; en gran soledad le dexo» (335) y le confiesa 
la ofensa cometida, pero no le da la oportunidad de que él la consuele, la juzgue o la condene. Melibea se autoimpone culpable, "De todo esto fui yo la causa» (337), pero no quiere saber el parecer paterno. Además, Melibea se suicida por amor a Calisto y no por haber perdido la virginidad, ni haber infringido la ley, ni ser la causante de la pérdida del honor familiar.

El llanto de Pleberio es uno de los espacios de mayor crítica de Rojas hacia el personaje del padre de la novela sentimental. Como decíamos antes, el llanto como colofón final parece eclipsar en cierta forma las apariciones de este personaje, muy especialmente porque numerosos críticos encuentran en Pleberio la prueba clave y final para defender la finalidad moral de La Celestina. En esta lectura contemporánea de la obra de Rojas prima el hecho de que un padre haya perdido a una hija y exprese su dolor, y no que la figura del padre se oponga a un modelo literario específico. Son cuatro los aspectos que quiero destacar del llanto de Pleberio: cómo se produce la ruptura con el canon y con el llanto tradicional, cómo se feminiza este personaje a través de su lloro, cómo el lamento de Pleberio representa el desorden y la ausencia de poder y autoridad y cuál es el papel del dinero y de la herencia en su lamento.

La comparación entre los llantos de Pleberio y el de las novelas sentimentales ha sido realizada en diversas ocasiones. Luis Miguel Vicente compara el lamento de Pleberio con el de la madre de Cárcel ${ }^{4}$ y afirma que «se ratifica la influencia de la obra de Diego de San Pedro en la de Rojas, pero también se pone de relieve el distanciamiento literario e ideológico de una y otra» (36). Este crítico ha observado que, en el discurso de Pleberio, faltan temas claves de la elegía y del llanto, como son los elogios de la difunta, pues Melibea ha perdido esas virtudes (36), y que para Pleberio no hay asomo de consolación (36). Wardropper, por otro lado, no cree el parlamento final de Pleberio sea en strictu sensu una elegía tradicional o planctus, aunque acepta que la influencia está ahí (142). Este crítico observa que Pleberio no busca la consolación normal, y observa que su dolor es personal y no público (143). Sea considerado un llanto propiamente o no, lo que me parece importante es que Rojas es capaz de utilizar un topos clásico y presente en la novela sentimental para rehacerlo y establecer así un diálogo crítico con la tradición.

Asimismo, la figura del padre llorando la pérdida de la hija es, como bien señala Iglesias, una "alteración de los papeles es una forma más de parodiar la novela sentimental, donde la figura paterna representa la ley inexorable que se opone al amor y es la madre la que expresa la compasión por el sufrimiento de los amantes» (99-100). Efectivamente, Pleberio desempeña en su última intervención un rol típicamente femenino, y a través del lamento Rojas feminiza a este personaje. Recordemos que las

4.- Jeanne Battesti Pelegrini muestra que los llantos de Cárcel sí siguen el modelo de planctus tradicional (238-244). 
cualidades de las madres, como son el perdón, la misericordia, y las súplicas ponían de relieve la crueldad, dureza e intransigencia del padre en la novela sentimental. Con esta inversión total de los papeles, Rojas le da a Pleberio un rol maternal y propone una caricatura del modelo, cuestionando la figura del padre de la novela sentimental.

En su lamento, Pleberio se queja de la muerte (341), de la fortuna (342) y del mundo (342) y hace patente su desesperación. Éste es casi el único punto en el que la crítica concuerda. Severin nota que "Pleberio seems to regress at the end of the lament into shock, incoherence and anger» (183); Vicente comenta la desesperación de este personaje (38), Dunn la confusión de sus pensamientos (415) y Michael Gerli su "false security» y su visión del mundo caótico (69). De un modo similar, Carlos Ripoll señala la acumulación en el discurso de Pleberio como una manera de intensificar el patetismo (71-72) así como «la disposición caótica de la realidad» de este personaje (75). Burke, siguiendo la tesis de Dorothy Severin, explica que "the overall message of Celestina would appear to be that there is no system which can be deemed as perfect (...) In had lachrymarum valle, in this fallen world, there is no scheme which finally can be seen complete and whole» (Burke 335). Por su parte, Fraker pone en oposición a Pleberio y la justicia (52). Estas lecturas aciertan en mostrar que Pleberio es todo lo contrario que un padre defensor de la ley: Pleberio no tiene control alguno de la situación y se muestra vulnerable, frágil e indefenso frente a la muerte de su hija, y la pérdida de su honor. Se da cuenta de una situación que no ha podido controlar, igual que no pudo gobernar su espacio ni el deseo de su única hija. La ley le va claramente en contra, ya que en lugar de mostrarsele como solución a los pecados cometidos, desaparece en su visión caótica del mundo, y así Pleberio se encuentra a sí mismo en un espacio del desorden y de confusión.

También el aspecto económico debe leerse como parte de la crítica al modelo del padre del género sentimental por parte de Rojas. Como bien afirma Dunn, el lamento de Pleberio muestra que Melibea «is not just the lost daughter of a grieving father, but the lost heir of a man of property» (414). Si recordamos las palabras del mismo Pleberio vemos el énfasis que él hace en la pérdida de su herencia "nuestro bien todo es perdido" (340), «¿Para quién edifiqué torres; para quién adquirí honnras; para quién planté árboles, para quién fabriqué navíos?» (314). En el Siervo, la Cárcel y Grisel, a los tres padres les daba igual perder sus riquezas y la única heredera del trono. Lo importante para ellos era no perder su honor y no parecer injustos. Pleberio, por lo contrario, entiende a Melibea como su único capital y siente que, perdiéndola a ella, lo ha perdido todo, a la vez que acepta su posición subjetiva al juzgar la situación de su hija. El aparente tono moralizante que se ha leído de Pleberio es también parte de la burla de Rojas: ¿Puede Pleberio dar discursos morales en su situación? ¿Este hombre que admite que, perdiendo a su hija, lo ha perdido todo, su 
dinero y su herencia? ¿Este padre que afirma que sus bienes y el amor que profesa hacia Melibea son mucho más importantes que las leyes morales de la época? Pleberio se presenta como lo contrario a una figura que pueda dar enseñanzas y juicios morales. Precisamente los padres estudiados de la novela sentimental defienden las leyes morales de forma tajante, por encima del amor hacia su propia descendencia y de sus riquezas. Pleberio hace todo lo contrario: defiende y pena por Melibea a pesar de que ella ha quebrado el honor familiar. Como dice Dorothy Severin, "Rojas is a writer who often employs a commponplace to destroy a commonplace» (183) y propone así en La Celestina un padre contrario a toda lección moral; Pleberio es un padre ridículo, grotesco y absurdo.

A lo largo de este artículo he mostrado la estrecha relación entre los padres de la novelas sentimentales Siervo, Cárcel y Grisel, por un lado, y, por el otro lado, la enorme distancia entre estos padres y Pleberio, el padre de Melibea en La Celestina. Esta comparación me ha servido para demostrar que Pleberio es un personaje que burla el modelo de padre autoritario, cruel y justiciero de la novela sentimental. Partiendo del análisis de la figura del padre en el Siervo, la Cárcel, Grisel, he observado cómo en estas obras el padre es un rey que sitúa la novela en un ambiente cortesano y de leyes morales muy determinadas, unas leyes que sus hijos deben seguir. El padre es una figura que representa esta ley, que inspira miedo y temor hacia a sus súbditos y familiares, que impide la consumación del amor de los amantes, que protege con recelo su espacio, el cuerpo y la honra de su único hijo o hija. Cuando descubre o sospecha que su hijo o hija ha quebrado las leyes, se llena de ira y furor. A pesar su deseo de actuar con serenidad, discreción, integridad y de ser equitativo, se deja llevar por sus pasiones: los padres en estas tres obras terminan siendo padres crueles e intransigentes; olvidan su papel como padres y sobreponen a sus sentimientos su rol como monarcas. Para ellos los bienes materiales, e incluso el fin de su propia descendencia, dejan de importar. Lo principal es la ley y defenderla y así ser respetados como reyes justicieros. En consecuencia, a estos reyes no les importa matar a sus propios sucesores, la sangre de su sangre, si con ello defienden su hono .

Pleberio es un padre contrario a este modelo, aunque naturalmente se inspira en el mismo. A pesar de que es un padre rico, honrado y que inspira temor a muchos de los otros personajes de La Celestina, Pleberio no es ni un rey ni tampoco un buen velador de la honra de su hija. A partir de su primera y segunda intervención descubrimos que es un padre descuidado, tranquilo y confiado. Pleberio no es un padre vigilante, no se ocupa de atender sus confines ni de custodiar su casa, ni tampoco vigila las relaciones que tiene su hija en edad de casarse. Pleberio es un padre convencido de la bondad de su hija y que pide consejo a su esposa. Además, Pleberio no inspira ningún tipo de temor a Melibea. En su llanto final se hace explícito que este personaje rompe completamente con el modelo 
de la novela sentimental. El lamento final hacia su hija lo feminiza y lo pone a la par con las madres de la novela sentimental, a la vez que pone de relieve la gran importancia que para Pleberio tiene no sólo la vida de la hija, sino también que no se pierdan sus bienes materiales, ganados con gran esfuerzo. A diferencia de los padres de Siervo, Cárcel y Grisel, que niegan sus sentimientos para defender la ley, y para quienes su honor está por encima de su herencia, Pleberio afirma que perdiendo a Melibea, su única heredera, lo ha perdido ya todo. 


\section{Obras citadas}

Alcázar López, Pablo y José A. González Núñez. «Introducción.» La historia de Grisel y Mirabella. Granada: Don Quijote, 1983. 7-51.

Battesti Pelegrin, Jeanne. "Tópica e invención: los lamentos de las madres en Cárcel de Amor de Diego se San Pedro.» Literatura Hispánica, Reyes Católicos y descubrimineto. Actas del Congreso Internacional sobre Literatura Hispánica en la época de los Reyes Católicos y el Descubrimiento. Ed. Manuel Criado del Val. Barcelona: PPU, 1989. 237-47.

Burke, James F. "Law of the Father-Law of the Mother in "Celestina».» Fernando de Rojas and Celestina: Approaching the Fifth Centenary. Eds. Corfis, Ivy A. and Joseph T. Snow. Madison: The Hispanic Seminar of Medieval Studies, 1993. 347-57.

Cortijo Ocaña, Antonio. La evolución genérica de la ficción sentimental. London: Tamesis, 2001.

Cvitanovic, Dinko. La novela sentimental española. Madrid: Prensa Española, 1973.

Deyermond, Alan. "Pleberio's Lost Investment: The Worldly Perspective of Celestina, Act 21.» MLN, 105.2 (1990): 169-79.

Dunn, Peter. «Pleberio's World.»PMLA, 91(1976) : 406-19.

Flightner, James A. «Pleberio» Hispania, 47 (1964): 79-81.

Flores, Juan de. La Historia de Grisel y Mirabella. Versión e introducción de Pablo Alcázar López y José A. González Núñez. Edición facsímil sobre la de Juan de Cromberger de 1529. Granada: Don Quijote, 1983.

Fraker, Charles. "The Importance of Pleberio's Soliloquy.» Romanishce Forschungen 78.4 (1966): 515-29.

GerLI, Michael. E. «Pleberio's Lament and Two Literary Topoi: Expositor and Planctus.» Romanische Forschungen, 88 (1976): 67-74.

Hook, David. "¿Para quién edifiqué torres? A Footnote to Pleberio's Lament.» Forum for Modern Language Studies, 14.1 (1978): 25-31.

IGLESIAS, Yolanda. Una nueva mirada a la parodia de la novela sentimental en La Celestina. Madrid: Iberoamericana, 2009.

LACARRA, María Eugenia. "La parodia de la ficción sentimental en La Celestina.» Celestinesca, 13.1 (1989): 11-30.

Lida de Malkiel, María Rosa. La originalidad artística de La Celestina. Buenos Aires: EUDEBA, 1962.

Mendeloff, Henry. "Pleberio in Contemporary Celestina Criticism.» Romance Note, 13 (1971): 369-73. 
RIPoll, Carlos. «El planto de Pleberio: aproximación estilística.» La Celestina a través del decálogo y otras notas sobre la literatura de la edad de oro. Nueva York: Las Américas, 1969. 167-87.

Rodríguez Cascante, Francisco. "La seducción de Celestina y el honor de Melibea en la recepción de Feliciano de Silva.» Celestinesca, 25. 1-2 (2001): 21-46.

Rodríguez Del Padrón, Juan. Siervo libre de amor. Edición: Antonio Prieto. Fijación del texto, notas y glosario: Francisco Serrano. Madrid: Castalia, 1976.

Roffé, Mercedes. La cuestión del género en Grisel y Mirabella de Juan de Flores. Newark: Juan de la Cuesta, 1996.

Rohland De Langbehn, Regula. La unidad genérica de la novela sentimental español de los siglos XV y XVI. Londres: Queen Mary and Westfield College, 1999.

RojAS, Fernando de. La Celestina. Edición: Dorothy S. Severin. 17a Edición. Madrid: Cátedra, Letras Hispánicas, 2008. (Primera edición: 1987).

San Pedro, Diego de. Cárcel de amor. Arnalte y Lucenda. Sermón. Edición: José Francisco Ruiz Casanova. 5a edición. Madrid: Cátedra, Letras Hispánicas, 2008. (Primera edición: 1995).

Severin, Dorothy S. "From the Lamentatios of Diego de San Pedro to Pleberio's Lament.» En The aAge of the Catholic Monarchs. 1474-1516. Literary Studies in Memory of Keith Whinnom. Eds. A. D. Deyermond e I. Macpherson. Liverpool: Liverpool UP, 1989.

Vicente, Luis Miguel. "El lamento de Pleberio: contraste y parecido con dos lamentos en Cárcel de amor.» Celestinesca, 12.1 (1988): 35- 43.

Wardropper, Bruce W. 1964. «Pleberio's Lament for Melibea and the Medieval Elegiac Tradition.» MLN, Spanish Issue, 79 (1964): 140-152. 


\section{Casas Aguilar, Anna, "Hacia una nueva subjetividad: La figura del padre en la novela sentimental y La Celestina», Celestinesca 40 (2016), pp. 53-72.}

\section{RESUMEN}

El presente artículo analiza la figura del padre en las novelas sentimentales Siervo libre de amor (1440) de Juan Rodríguez del Padrón, Cárcel de amor (1492) de Diego de San Pedro y La Historia de Grisel y Mirabella (1495) de Juan de Flores con el fin de contrastar a Pleberio, padre de Melibea en La Celestina, con el modelo de padre que nos ofrecen estas novelas sentimentales. Mi argumento es que la figura del padre en La Celestina es una parodia de la figura paterna en la novela sentimental. Asimismo, con mi lectura, quiero demostrar que en Pleberio encontramos una nueva subjetividad en la que el padre no se preocupa por representar la ley y la autoridad y ser una figura imparcial, sino que el padre en la obra de Fernando de Rojas asume una posición más humana en relación con la muerte de su hija.

PAlabras Clave: Figuras del padre, novela sentimental, Pleberio, Siervo libre de amor, Cárcel de amor, La Historia de Grisel y Mirabella.

\section{ABSTRACT}

This article examines the figure of the father in the sentimental novels Siervo libre de amor (1440) by Juan Rodríguez del Padrón, Cárcel de amor (1492) by Diego de San Pedro and La Historia de Grisel y Mirabella (1495) by Juan de Flores in order to contrast those figures with the character of Pleberio in La Celestina. I argue that the father in La Celestina should be read as a parody of the figure of the father in the sentimental novel genre. Moreover, I propose that Pleberio represents a new form of subjectivity, in which the father is not worried about representing the law and authority nor about being impartial. In Fernando de Rojas' text, the father instead he takes a more human stance regarding his daughter's death.

KEY WORDS: Father figures, sentimental novel, Pleberio, Siervo libre de amor, Cárcel de amor, La Historia de Grisel y Mirabella.

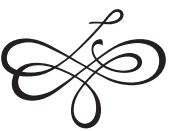

